\title{
Vehicle lightweighting through the use of molybdenum-bearing advanced high-strength steels (AHSS)
}

\author{
Alexander Patrick Hardwick ${ }^{1}$ Tim Outteridge ${ }^{2}$
}

Received: 18 May 2015 / Accepted: 9 September 2015 /Published online: 23 September 2015

(C) The Author(s) 2015. This article is published with open access at Springerlink.com

\begin{abstract}
Purpose The past two decades have seen growing pressure on vehicle manufacturers to reduce the environmental impact of their vehicles. One effective way to improve fuel efficiency and lower tailpipe emissions is to use advanced high-strength steels (AHSS) that offer equal strength and crash resistance at lower mass. The present study assesses the life cycle environmental impacts of two steel grades considered for the B-pillar in the Ford Fusion: A press-hardened boron steel design as used in the previous model of the vehicle and a hydroformed component made from a mix of the molybdenum-bearing dual phase steels DP800 and DP1000.

Methods Information related to the component masses and grades was provided by Ford. Process models for the steelmaking process, finishing, forming, vehicle use and end of life were created in the GaBi LCA software tool. Sensitivity analyses were conducted on the impact of the hydroforming process for the new component, for which only proxy data were available and on the mix of DP800 and DP1000 in the Bpillar. Results have been presented for the environmental impact categories deemed most relevant to vehicle use.

Results and discussion The life cycle assessment showed that the new DP800/DP1000 B-pillar design has a lower impact for the environmental impact categories assessed. Overall, the global warming potential (GWP) of the new DP800/DP1000
\end{abstract}

Responsible editor: Chris Bayliss

Alexander Patrick Hardwick

alex.hardwick@thinkstep.com

1 Thinkstep, Electric Works, Sheffield Digital Campus, Sheffield S1 2BJ, UK

2 International Molybdenum Association (IMOA), 454-458 Chiswick High Road, London W4 5TT, UK design was $29 \%$ lower than the boron steel design over the full life cycle of the vehicle. The use phase was found to be the major source of environmental impacts, accounting for $93 \%$ of the life cycle GWP impact. The $4 \mathrm{~kg}$ weight saving accounts for the majority of the difference in impacts between the two B-pillar designs. Impacts from manufacturing were also lower for the new design for all of the impact categories assessed despite the higher alloy content of the steel. A sensitivity analysis of the hydroforming process showed that even if impacts from forming were $100 \%$ greater than for press hardening, the GWP from production of the new B-pillar design would still be lower than the boron steel version.

Conclusions and recommendations The molybdenumbearing DP1000/DP800 B-pillar was found to have lower life cycle and production impacts than the previous boron steel design. The assessment indicates that significant improvements in the environmental impacts associated with the body structure of vehicles could be made through the increased use of AHSS in vehicles without compromising crash performance.

Keywords Automotive $\cdot$ High-strength steel · Lightweighting $\cdot$ Molybdenum

\section{Introduction}

Over the past two and a half decades, the transport sector has become a growing source of concern for governments, consumers and other stakeholders seeking to tackle the combined pressures of climate change, air pollution and resource use. The European Union estimates that road transport contributes around $20 \%$ of the EU's total carbon dioxide emissions, with passenger cars responsible for around $12 \%$ of the total (EU 2015). Furthermore, emissions from road transport in the EU 
increased by $26 \%$ between 1990 and 2004, bucking the general trend of a $5 \%$ reduction across all sectors, and accounted for $60 \%$ of oil consumption in the region (EU 2007). Similar trends are observed in the USA, where energy consumption from transportation grew by an average of $1.3 \%$ annually between 1970 and 2007, driven by an increasing demand for personal travel (EIA 2015), and in China where car ownership increased from below 15 million in 1999 to more than 120 million in 2013 (Bloomberg 2013) leading to well-publicised issues with air quality in major cities (BBC 2014; Forbes 2014; He et al. 2010).

Mitigation strategies aimed at reducing the environmental impacts associated with transport can be categorised into three broad categories: Reducing the need for transportation, increasing the use of low-impact transport modes such as walking and cycling and improving vehicle technology and fuels (de Wilde 2013). Within this third category, improvements can be made through abatement technologies to reduce tailpipe emissions such as catalytic convertors (Bosteels and Searles 2002), changes in the composition of fuels themselves such as reducing sulphur in diesel (Blumberg et al. 2003), the use of electric or hybrid vehicles (Hawkins et al. 2012) and improvements in vehicle fuel efficiency through measures such as reduced rolling resistance (Bridgestone 2013) and vehicle lightweighting (ThyssenKrupp 2009), which forms the focus of this study.

Vehicle lightweighting is a widely used strategy for reducing the environmental impact of vehicles and may be achieved through a mix of material choice and component redesign. Material choice may be limited in some critical components of the vehicle's body structure due to strength and crash resistance requirements.

One example is a vehicle's B-pillar; this provides vertical support between the front and rear sections of the vehicle and plays a key role in protecting the occupants and maintaining the structural integrity of the vehicle during a side impact. For components such as the vehicle B-pillar, lightweighting can be achieved through the use of advanced high-strength steels (AHSS), which can offer equal or improved crash resistance at lower thicknesses and consequently lower masses.

This paper presents the results of a life cycle assessment study commissioned by the International Molybdenum Association (IMOA) in 2014 to assess the life cycle impacts of two B-pillar designs from different generations of the Ford Fusion.

\section{Methods}

\subsection{Goal}

The project's aim was to assess the life cycle cradle-to-grave impacts of two designs of the Ford Fusion B-pillar. The study was commissioned by IMOA to help its members and wider stakeholders understand the quantifiable environmental implications of using AHSS containing molybdenum in the body structure of vehicles.

\subsection{Product system, functional unit and boundaries}

\subsubsection{Description of B-pillar and functional unit}

The Ford Fusion is a mid-sized passenger car that has been produced by Ford since 2005. Primarily sold in the Americas, the first-generation Ford Fusion was sold between 2006 and 2013 , including an update of the vehicle in 2010. In this version of the vehicle, the B-pillar was made of press-hardened boron steel and each B-pillar had a mass of $13.3 \mathrm{~kg}$, with both B-pillars representing around $8 \%$ of the total mass of the body in white (around $325 \mathrm{~kg}$ ). For the development of the secondgeneration Ford Fusion, which has been produced since 2013 and is sold globally as the fourth-generation Ford Mondeo, Ford instigated a program to redesign the body in white (BIW) of the vehicle. The objective of the BIW redesign was to improve the safety of the vehicle; reduce noise, vibration and harshness (NVH) associated with the vehicle; and make other improvements while limiting any increase in vehicle mass. For the B-pillar, this meant that the component was redesigned as a hydroformed component comprising a mix of two AHSS steel grades: the dual phase steels DP800 and DP1000 (Ford 2012).

The redesigned component had a mass of $9.3 \mathrm{~kg}$ making it $4 \mathrm{~kg}(30 \%)$ lighter than the previous generation; however, the AHSS grades contain greater concentrations of alloying elements than typical boron steel grades. DP800 may contain up to $1 \%$ chromium and molybdenum combined (with a typical molybdenum content of around $0.18 \%$ ) and $2.5 \%$ manganese by mass with a total alloy content between 2 and $3 \%$. DP1000 may contain up to $1.4 \%$ chromium and molybdenum combined (with a typical molybdenum content of around $0.33 \%$ ) and $2.9 \%$ manganese by mass (BSI 2013) although typical manganese content is likely to be lower. Total alloy content is generally between 2 and $3 \%$. Boron steel grades used in automotive applications generally have lower alloy contents. For example, sample compositions of the non-standardised 22MnB5 grade contain between 1 and $1.4 \%$ manganese, $0.11-0.25 \%$ chromium and $0.0008-0.005 \%$ boron with total alloy content between 1.5 and $2.5 \%$ (Ruukki 2015; Salzgitter 2015; SSAB 2015).

The two components are functionally equivalent, with crash tests showing maximum intrusion due to a side impact (the measure of how far inwards the component is deformed) being equivalent at the base of the pillar, with a reduction in maximum intrusion of $64 \mathrm{~mm}$ for the new design at the top of the pillar (Ford 2012). The B-pillar redesign was one part of a wider redesign of the body in white but is not believed to have 
had any direct knock-on effects that required redesign of other components. Consequently, it is considered reasonable to compare the two components in isolation without including the rest of the body in white.

The functional unit chosen for the study was one B-pillar in a Ford Fusion over a total lifetime mileage of 200,000 km and a 10 -year period, noting the functional equivalence between the two generations of the vehicle established by Ford. Estimates of lifetime vehicle mileage vary between manufacturers with typical values for passenger cars in the range of 150,000 and $300,000 \mathrm{~km}$. For this study, a value of 200 , $000 \mathrm{~km}$ has been used, which is in line with standard maintenance schedules for the Ford Fusion which run up to 241, $000 \mathrm{~km}(150,000 \mathrm{mi})$ (Ford 2015) and other studies of midsized passenger vehicles (Daimler 2007; SLC 2009).

\subsubsection{System boundary and assumptions}

The system boundary of the LCA included production of all upstream materials required to produce steel; steelmaking and casting; rolling, finishing and forming of the components; vehicle use over $200,000 \mathrm{~km}$ including fuel production and combustion; and end of life.

Steel production of the relevant grades was assessed using models developed by thinkstep (formerly PE International) in the GaBi LCA software with the secondary steelmaking process adapted to reflect the alloy composition of the grades in question. Other elements of steelmaking were considered to be identical for all grades. Secondary data sourced from the $\mathrm{GaBi}$ database and reflecting global average production were used to model the upstream production of alloys, with the notable exceptions of ferrovanadium and ferromanganese for which only data for South African production were available and molybdenum where data on ferromolybdenum were provided by IMOA. This data is considered to be geographically representative as steel and alloys are globally traded commodities. All primary data and upstream datasets are less than 5 years old with the exception of the worldsteel value of scrap dataset used to calculate net scrap credit/burdens which is 8 years old but is considered to have the widest geographical and technological coverage for datasets currently available so has been included despite its age.

Based on technical drawings provided by Ford, the new Bpillar was calculated to comprise $76 \%$ DP800 and $24 \%$ DP1000. The sensitivity of the results to differing proportions of these grades was investigated as a component of the analysis.

Information on the composition of the individual steel grades was sourced from a mix of publically available grade composition data and data provided directly to the authors. Alloy compositions stating average or typical values were used wherever possible. Composition data stating maximum alloy contents (e.g. alloy standards) were also considered and used to cross-reference other data sources.

Data on the hydroforming technique used to form the new DP800/DP1000 component were not available. Consequently, a conventional automotive stamping and forming process was modelled for both components. The potential effect of this exclusion on the results is discussed in the analysis. Any differences in assembly processes between the two B-pillar designs have not been included in this assessment.

The use phase fuel consumption attributable to the B-pillar was estimated using fuel reduction values (FRVs). FRVs are used by the automotive industry to estimate the reduction in
Fig. 1 Life cycle global warming potential results

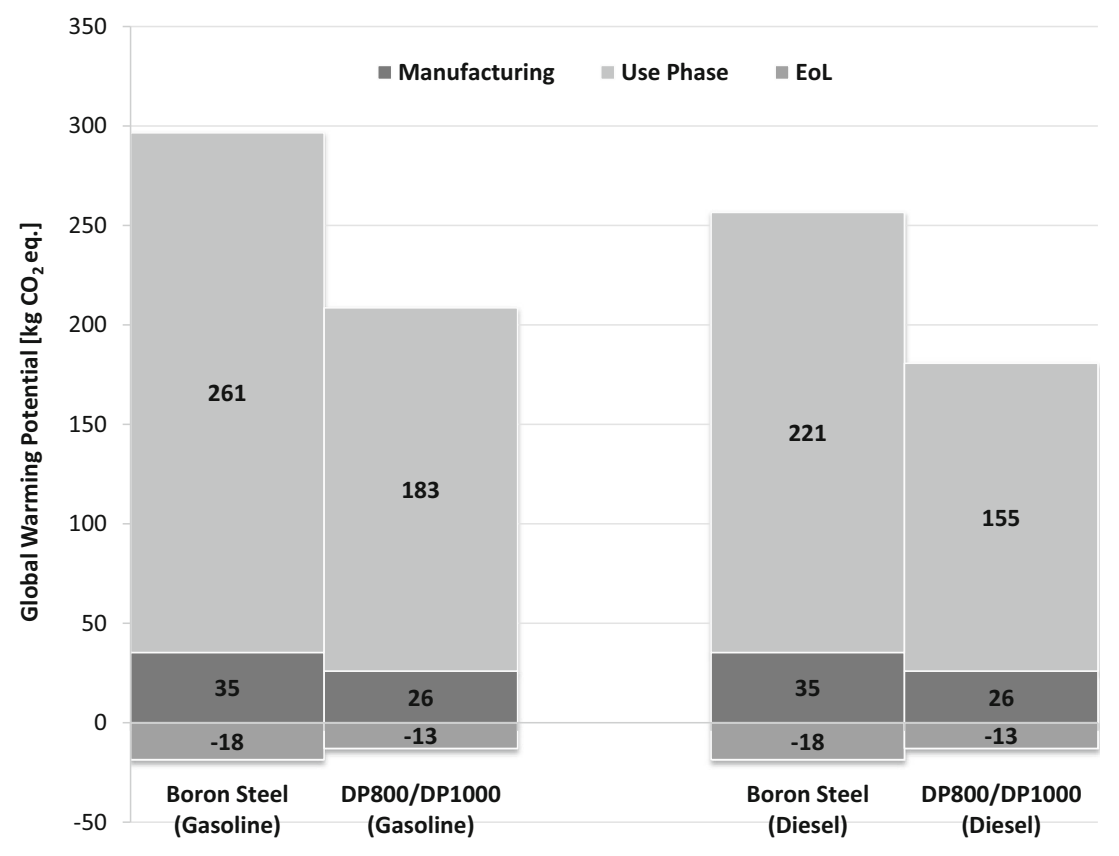


Fig. 2 Life cycle acidification potential results

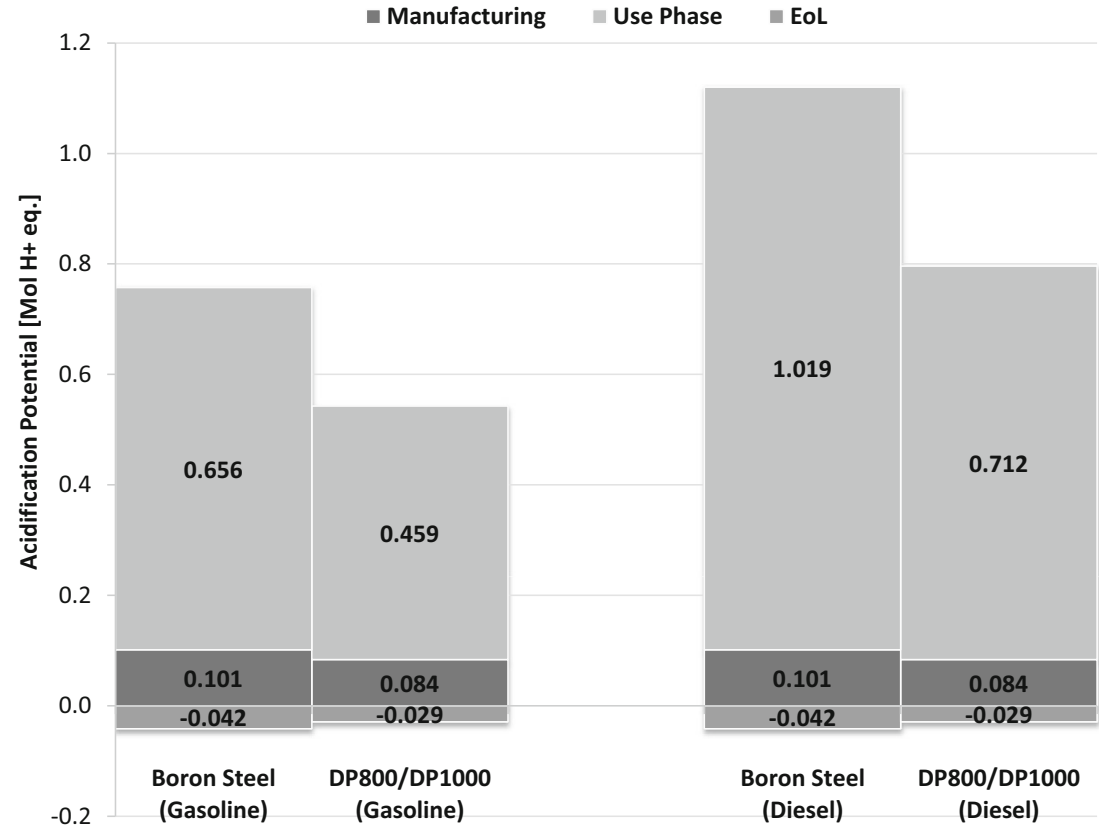

fuel consumption resulting from vehicle lightweighting for a given distance. FRVs can either include or exclude powertrain resizing based on the reduction in vehicle mass (Koffler 2010). In this study, it has been assumed that the vehicle is driven under European average conditions, so FRVs calculated based on the New European Driving Cycle (NEDC) have been used. The NEDC is a driving cycle model developed to simulate typical vehicle use and is used within Europe to assess the emission profiles of vehicles (EU 2007).

From the NEDC, typical FRVs without powertrain resizing of $0.15 \mathrm{l} /(100 \mathrm{~km} * 100 \mathrm{~kg})$ for gasoline vehicles and $0.12 \mathrm{l} /$ (100 km*100 kg) for diesel vehicles can be calculated, while
FRVs with powertrain resizing are $0.351 /(100 \mathrm{~km} * 100 \mathrm{~kg})$ for gasoline vehicles and $0.28 \mathrm{l} /(100 \mathrm{~km} * 100 \mathrm{~kg})$ for diesel vehicles (Koffler 2010). In this study, FRVs that include powertrain resizing were used to reflect the reduction in engine size and improvement in fuel efficiency in the secondgeneration Ford Fusion whereby 2.5 to 3.51 engines were replaced by 1.5 to 2.51 engines with improved fuel economy, but almost identical horsepower, making them functionally equivalent. Results were calculated for both gasoline and diesel drivetrains; however, it should be noted that the diesel engine is only available in Europe and other regions where it is sold as the fourth-generation Mondeo. Results for diesel
Fig. 3 Life cycle eutrophication potential results

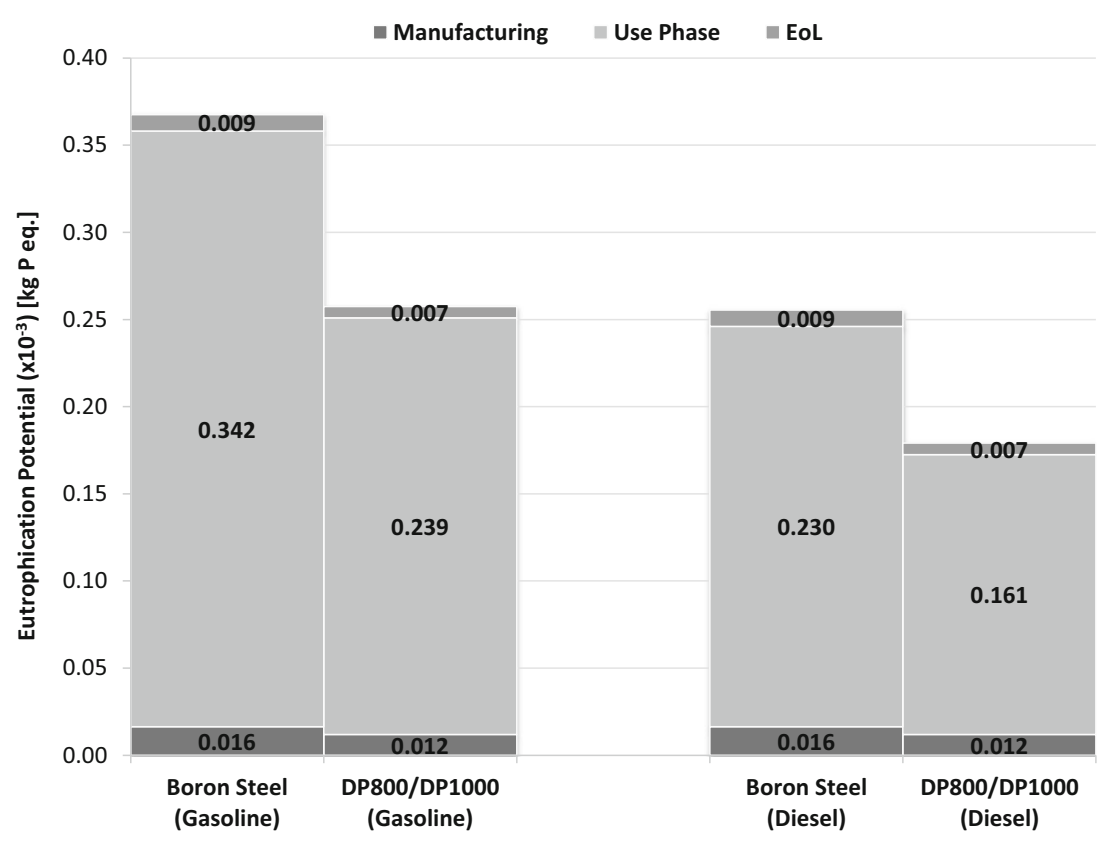


Fig. 4 Life cycle photochemical formation results

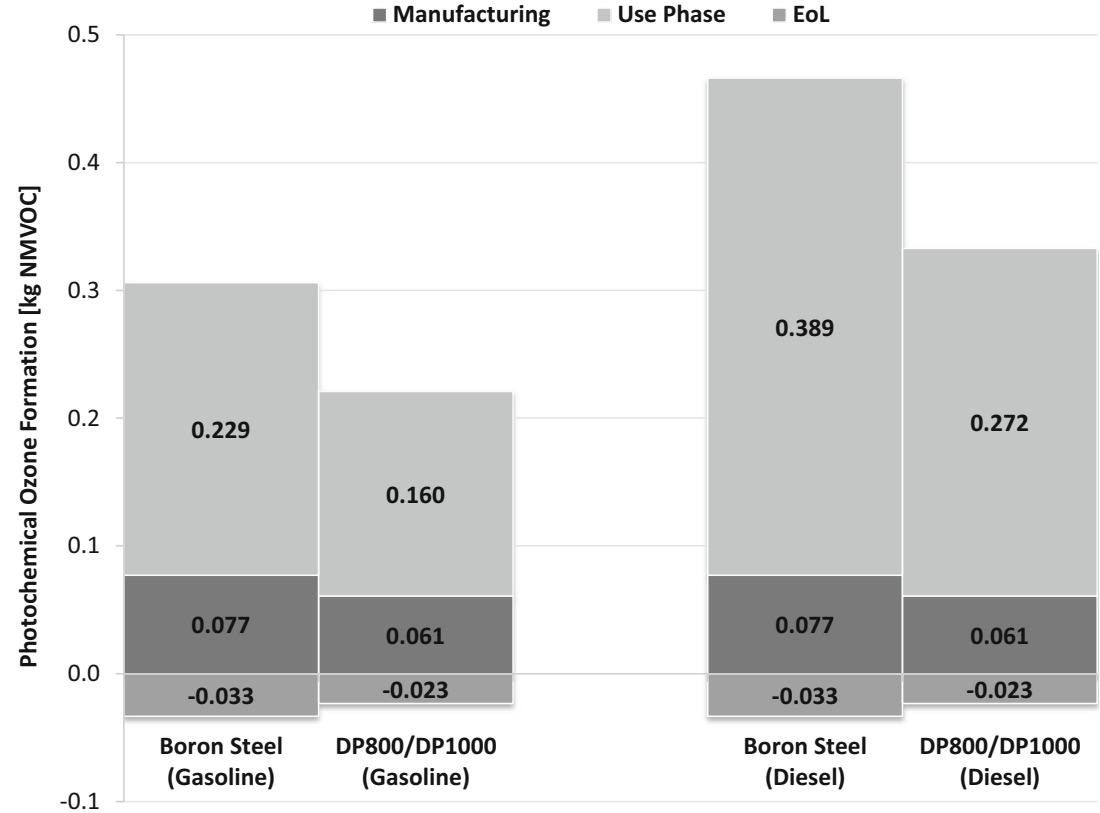

powertrain for the previous B-pillar design are therefore only indicative as the third-generation Mondeo was not identical to the first-generation Ford Fusion. Results without powertrain resizing have been included as a part of a sensitivity analysis as this is regarded as a key use phase assumption.

At end of life, a steel recycling rate of $95 \%$ was assumed. This is in line with the European Union's end-of-life vehicle directive which mandates a $95 \%$ recovery rate for all vehicles from 1 January 2015 (EU 2000) and a rate of $95 \%$ used by WorldAutoSteel for end-of-life steel scrap recycling in their autoLCA tool (autoLCA 2013). The benefits of recycling steel at end of life were assessed based on a net scrap approach taking into account the scrap input required to produce new steel. Both products were modelled as being produced via the $\mathrm{BF} / \mathrm{BOF}$ route, the main production route for automotive strip/ coil products, with an average scrap input of $12 \%$. The global average value of scrap developed by the World Steel Association was used to calculate the overall environmental benefits/burdens attributable to recycling at end of life.

\subsection{Life cycle impact assessment methods}

The environmental impact assessment categories and life cycle inventory indicators selected for the assessment
Fig. 5 Life cycle primary energy demand

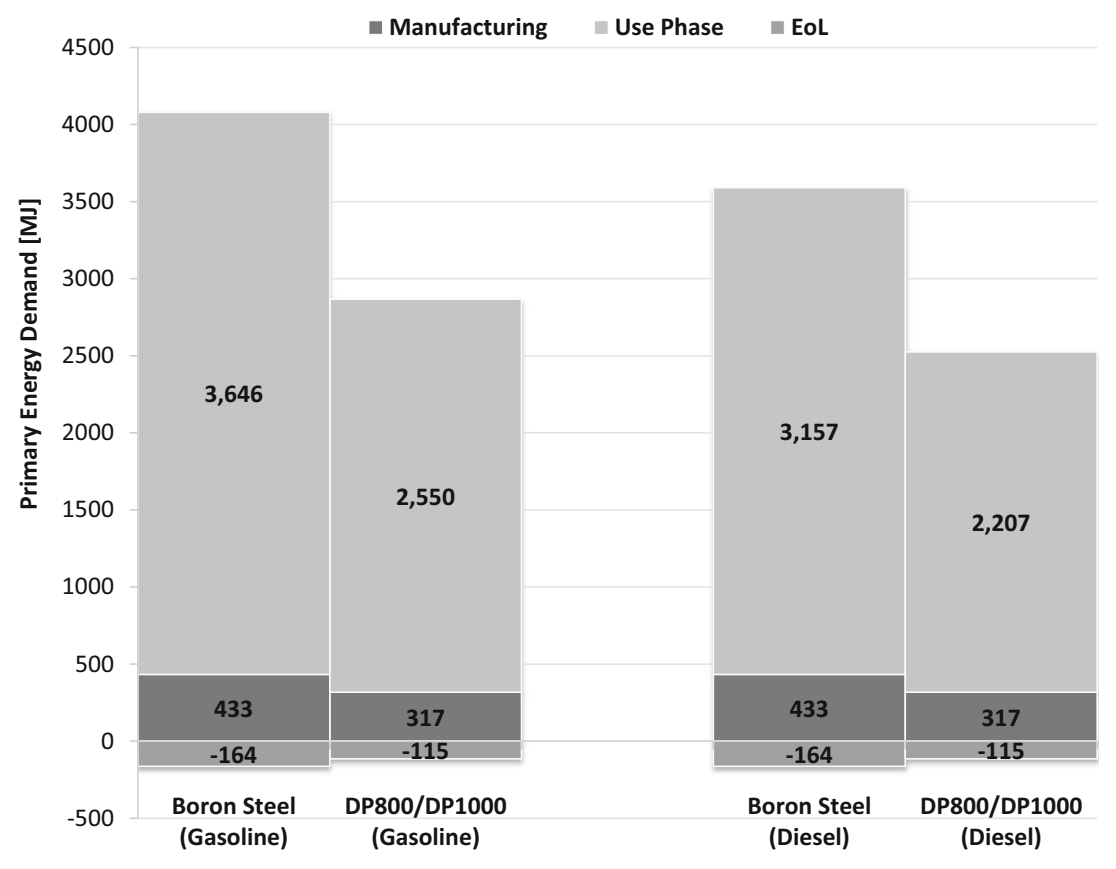


Table 1 Full life cycle results for the two B-pillar designs

\begin{tabular}{|c|c|c|c|c|c|c|}
\hline & \multicolumn{3}{|l|}{ Petrol drivetrain } & \multicolumn{3}{|l|}{ Diesel drivetrain } \\
\hline & $\begin{array}{l}\text { Baseline-boron } \\
\text { steel }\end{array}$ & $\begin{array}{l}\text { New design-DP800/ } \\
\text { DP1000 }\end{array}$ & $\begin{array}{l}\text { Percentage } \\
\text { change }\end{array}$ & $\begin{array}{l}\text { Baseline-boron } \\
\text { steel }\end{array}$ & $\begin{array}{l}\text { New design-DP800/ } \\
\text { DP1000 }\end{array}$ & $\begin{array}{l}\text { Percentage } \\
\text { change }\end{array}$ \\
\hline $\begin{array}{l}\text { Global warming potential } \\
{\left[\mathrm{kg} \mathrm{CO}_{2} \text { eq. }\right]}\end{array}$ & 278 & 196 & $-29.6 \%$ & 238 & 168 & $-29.6 \%$ \\
\hline $\begin{array}{l}\text { Acidification potential } \\
{[\text { Mol. H+ eq. }]}\end{array}$ & 0.715 & 0.513 & $-28.3 \%$ & 1.08 & 0.767 & $-28.9 \%$ \\
\hline $\begin{array}{l}\text { Eutrophication potential } \\
\text { [kg P eq. }]\end{array}$ & $3.68 \times 10^{-4}$ & $2.57 \times 10^{-4}$ & $-30.0 \%$ & $2.55 \times 10^{-4}$ & $1.79 \times 10^{-4}$ & $-29.9 \%$ \\
\hline $\begin{array}{l}\text { Photochemical formation [ } \mathrm{kg} \\
\text { NMVOC] }\end{array}$ & 0.273 & 0.197 & $-27.5 \%$ & 0.433 & 0.309 & $-28.5 \%$ \\
\hline $\begin{array}{l}\text { Primary energy demand } \\
\text { (total) }[\mathrm{MJ}]\end{array}$ & 3915 & 2753 & $-29.7 \%$ & 3426 & 2410 & $-29.6 \%$ \\
\hline $\begin{array}{l}\text { Primary energy demand } \\
\text { (non-renewable) [MJ] }\end{array}$ & 3760 & 2643 & $-29.7 \%$ & 3289 & 2313 & $-29.7 \%$ \\
\hline
\end{tabular}

were global warming potential, acidification potential, photochemical ozone formation, eutrophication potential and primary energy demand. Global warming potential was included as it is the category used to quantify climate change; which is a primary environmental concern related to vehicles for governments and legislators. $\mathrm{CO}_{2}$ emissions are also increasingly subject to strict limits and, in some countries, are used as a basis for vehicle taxation. Acidification potential, photochemical ozone formation and eutrophication potential are all linked to airborne emissions that result from the combustion of fuels, such as $\mathrm{NO}_{\mathrm{x}}, \mathrm{SO}_{\mathrm{x}}$ and volatile organic compounds that are regulated by vehicle emission standards. Primary energy demand is reported as a measure of the energy efficiency of the whole system from cradle to grave. The characterisation methodologies used for the four impact categories reported in this assessment are those recommended in the ILCD handbook (ILCD 2011).

\section{Results}

Results generated for the full life cycle of the vehicle B-pillar indicate that the new DP800/DP1000 design has a lower impact for the four impact categories assessed as well as primary energy demand. Figures 1, 2, 3, 4 and 5 illustrate the impacts for one B-pillar for both gasoline and diesel drivetrains, with results broken down into manufacturing, use and end of life (see also Table 1).

These figures show that the use phase is the dominant contributor to the life cycle impact of the B-pillar. Over a 200, $000 \mathrm{~km}$ vehicle lifetime and assuming a gasoline drivetrain, the use phase accounts for $93 \%$ of the life cycle GWP of the DP800/DP1000 B-pillar and $94 \%$ of the GWP of the boron steel B-pillar. For all categories included in this study, the use phase accounts for more than $80 \%$ of total impacts. Consequently, the reduction in fuel consumption resulting from the $4 \mathrm{~kg}$ weight saving and the related powertrain resizing accounted for the majority of the difference in impacts between the two B-pillar designs.

A credit at end of life related to steel recycling is seen in Figs. 1, 2, 4 and 5 as a negative value below the $x$-axis. This represents the environmental savings in the next life cycle due to the reduced requirement for steel from virgin material. The exception to this is eutrophication potential, where the value of scrap process used to calculate the end-of-life credits attributable to steel recycling did not result in a negative eutrophication potential. This is because the eutrophication potential of the electricity consumed in producing steel from scrap in an electric arc furnace is higher than the eutrophication potential of producing blast furnace steel.

Results for the two B-pillar designs indicate that the new design is also likely to have lower environmental impacts

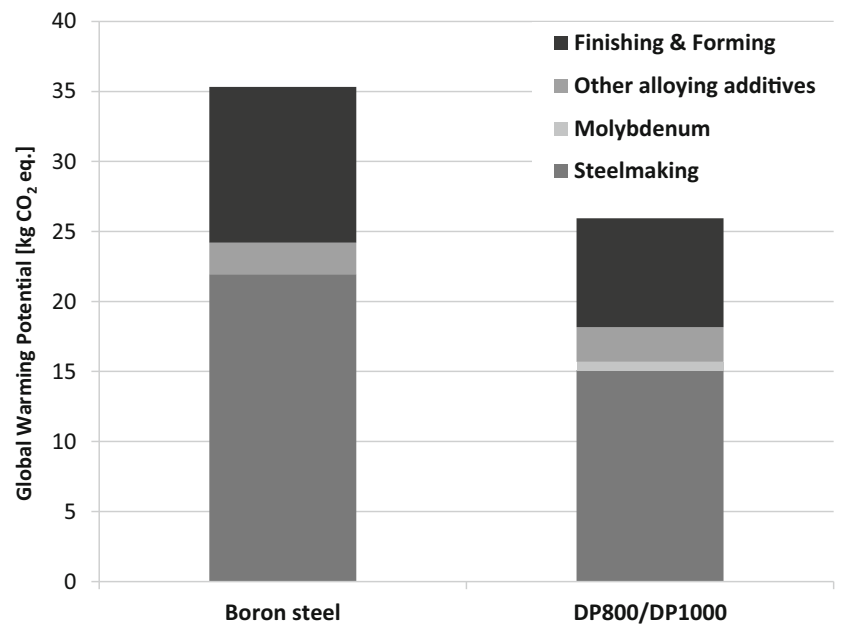

Fig. 6 Global warming potential of manufacturing (cradle to gate) 
Fig. 7 Sensitivity analysis inclusion/exclusion of powertrain resizing in fuel reduction values

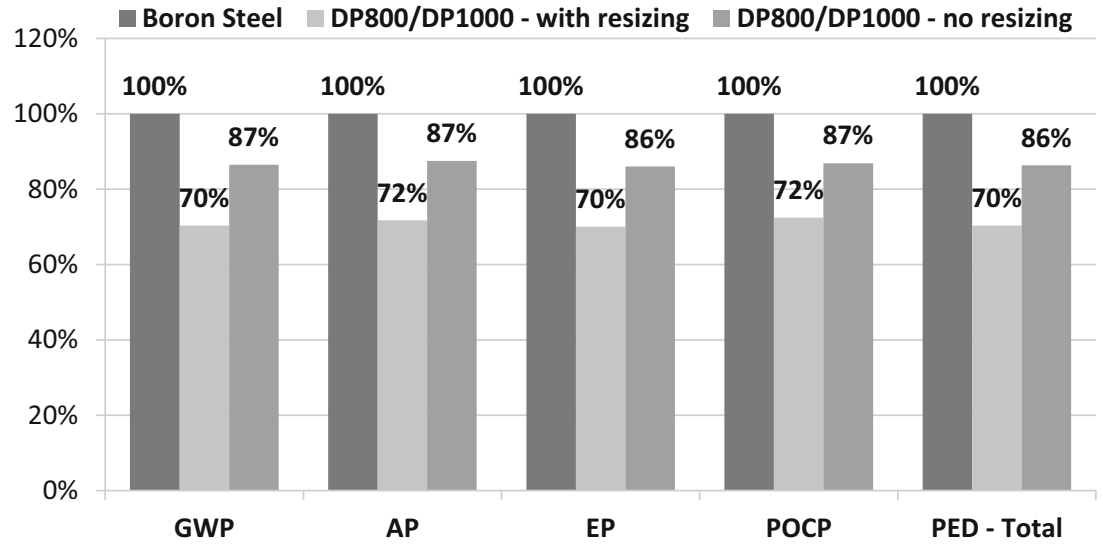

during production. Figure 6 illustrates the global warming potential due to manufacturing only and shows the contribution made by molybdenum and other alloying elements. The small increase in impacts due to the greater use of alloying elements including molybdenum in the DP800 and DP1000 steel grades is more than compensated for by the reduction in the material required for the B-pillar and the consequent reduction in impacts from ironmaking and secondary steelmaking. Similar trends were observed for all the other impact categories assessed, with the new design having lower impacts in all cases.

\section{Discussion and sensitivity}

As previously stated, data on the impacts associated with the hydroforming process used to manufacture the new component were unavailable. For the purposes of this study, forming for both components was estimated with a conventional forming process. A sensitivity analysis showed that, given the difference between the production impacts of the two designs, even doubling the impact from forming (i.e. a $100 \%$ increase) would not result in a global warming potential for production higher than the original boron steel design. For acidification and eutrophication potentials, the sensitivity analysis found that production impacts are higher for the new design when forming impacts were increased by $50 \%$. For photochemical ozone formation and primary energy demand, the crossover point occurs when forming impacts are above 80 and $90 \%$, respectively.

A second sensitivity analysis was carried out to investigate the influence on the results of a change in the proportion of DP800 and DP1000 used in the B-pillar. DP1000 was found to have a marginally higher impact than DP800, but assuming that the component was $100 \%$ DP1000 resulted in an increase of less than $5 \%$ in the production impacts of the B-pillar for all metrics assessed (less than $1 \%$ over the full life cycle of the component).
The third sensitivity analysis investigated the effect of using fuel reduction values without powertrain resizing. As detailed in Sect. 2.2.2, FRVs without powertrain resizing are estimated to be $0.15 \mathrm{l} /(100 \mathrm{~km} * 100 \mathrm{~kg})$ for gasoline vehicles and $0.12 \mathrm{l} /(100 \mathrm{~km} * 100 \mathrm{~kg})$ for diesel vehicles. FRVs with powertrain resizing were assumed to be $0.35 \mathrm{l} /$ (100 km*100 kg) for gasoline vehicles and $0.28 \mathrm{l} /$ $(100 \mathrm{~km} * 100 \mathrm{~kg})$ for diesel vehicles. This sensitivity analysis showed that the reduction in impacts was 13-14\% without powertrain resizing compared to 28-30\% with powertrain resizing (Fig. 7). This illustrates that the DP800/DP1000 is still likely to result in lower environmental impacts than the boron steel design but that significantly greater benefits are likely to be achieved with powertrain resizing also taking place. Other areas of variation in the use phase include the total distance driven by the vehicle and the driving cycle. These assumptions are likely to be the same for both vehicles, so could potentially affect the proportion of the total impact attributable to the use phase, but are unlikely to result in significant changes to the overall trends observed.

Overall, the results indicated that the $4 \mathrm{~kg}$ weight reduction leads to considerable use phase savings, which drive the difference in impact between the two components. The GWP saving for both B-pillars in the Ford Fusion over a 200, $000 \mathrm{~km}$ total driving distance was calculated to be $165 \mathrm{~kg}$ $\mathrm{CO}_{2} \mathrm{e}$ for a petrol drivetrain and $141 \mathrm{~kg} \mathrm{CO}_{2} \mathrm{e}$ for a diesel drivetrain. This is equivalent to driving the vehicle over 1 , $000 \mathrm{~km}$ assuming a standard driving cycle.

\section{Conclusions}

The assessment of the life cycle impact of selected environmental metrics relevant to the automotive sector found that the new hydroformed DP800/DP1000 B-pillar design used in the second-generation Ford Fusion Mondeo has notably lower impacts than the previous boron steel design. Most of these savings are due to reductions in use phase impacts due to the 
lighter weight and resized powertrain of the new design that uses molybdenum-bearing advanced high-strength steels.

Focusing only on the impacts due to production, the small increase in impacts due to the increased use of alloying elements including molybdenum was found to be more than compensated for by the savings in ironmaking and secondary steelmaking. Additional impacts from the hydroforming process that have not been taken into account might increase the overall results but are unlikely to cancel out the reduction in impacts associated with the new component.

These environmental improvements were achieved while also improving the crash performance of the B-pillar during side impacts. Ford also estimates that the redesign has yielded significant cost savings, indicating that the switch to a DP800/ DP1000 B-pillar design is likely to have provided benefits beyond the reduced environmental impacts identified through this study. This demonstrates the potential improvements that can be achieved by using AHSS with innovative manufacturing techniques and the contribution that molybdenum can make in supporting similar innovations in the future.

Open Access This article is distributed under the terms of the Creative Commons Attribution 4.0 International License (http:// creativecommons.org/licenses/by/4.0/), which permits unrestricted use, distribution, and reproduction in any medium, provided you give appropriate credit to the original author(s) and the source, provide a link to the Creative Commons license, and indicate if changes were made.

\section{References}

autoLCA (2013) Life cycle energy and greenhouse gas (GHG) assessments of automotive material substitution: user guide for version 4 of the WorldAutoSteel Energy and GHG Model. http://www. autolca.com $/ 18$

BBC (2014) China to scrap millions of cars to improve air quality http:// www.bbc.co.uk/news/business-27583404. Last accessed 23 April 2015

Bloomberg (2013) China vehicle population hits 240 million as smog engulfs cities http://www.bloomberg.com/news/articles/2013-0201/china-vehicle-population-hits-240-million-as-smog-engulfscities. Statistics based on statement from China's Ministry of Public Security. Last accessed 24 April 2015

Blumberg KO, Walsh, MP, Pera C (2003) Low-sulfur gasoline \& diesel: the key to lower vehicle emissions. International Council on Clean Transportation

Bosteels D, Searles RA (2002) Exhaust emission catalyst technology. Platin Met Rev 46(1):27-36

Bridgestone (2013) Environmental commitment and performance. Bridgestone Europe, 2013

BSI (2013) BS EN 10338:2013 - Hot rolled and cold rolled non-coated flat products of multiphase steels for cold forming. Technical delivery conditions. BSI, London, UK

Daimler (2007) Environmental Certificate Mercedes Benz C-Class https://www.daimler.com/Projects/c2c/channel/documents/
2003760_Environmental_Certificate_Mercedes_Benz_C_Class. pdf. Last accessed 12 May 2015

de Wilde HPJ (2013) Policy options to reduce passenger cars $\mathrm{CO}_{2}$ emissions after $2020 \mathrm{http}: / /$ www.ecn.nl/docs/library/report/2013/e13005.pdf

EIA (2015) Annual energy outlook 2015 with projections to $2040 \mathrm{http} / / /$ www.eia.gov/forecasts/aeo/pdf/0383(2015).pdf

EU (2000) Directive 2000/53/EC of the European Parliament and of the Council of 18 September 2000 on end-of-life vehicles

EU (2007) Regulation 715/2007 of the European Parliament and of the Council of 20 June 2007 on type approval of motor vehicles with respect to emissions from light passenger and commercial vehicles (Euro 5 and Euro 6) and on access to vehicle repair and maintenance information

EU (2015) Reducing CO2 emissions from passenger cars http://ec. europa.eu/clima/policies/transport/vehicles/cars/index_en.htm. Last accessed 23 April 2015.

Forbes (2014) China's war on air pollution shows more promise than reports indicate. http://www.forbes.com/sites/ckgsb/2014/08/06/ chinas-air-pollution-better-than-reports-indicate. Last accessed 24 April 2015

Ford (2012) Ford Fusion car body presentation. Presented at EuroCarBody 2012 - 14th Global Car Body Benchmarking Conference

Ford (2015) Ford maintenance schedules for fleet vehicles. http://www. fleet.ford.com/partsandservice/maintenance-schedules/. Last accessed 12 May 2015

Hawkins TR, Gausen OM, Strømman AH (2012) Environmental impacts of hybrid and electric vehicles - a review. Int J Life Cycle Assess 17: 997-1014

He K, Yao Z, Zhang Y (2010) Characteristics of vehicle emissions in china based on portable emission measurement system. Presented at 19th Annual International Emission Inventory Conference "Emissions Inventories - Informing Emerging Issues" Sep 27-30 2010. http://www.epa.gov/ttnchie1/conference/ei19/session6/he.pdf

ILCD (2011) European Commission-Joint Research Centre - Institute for Environment and Sustainability: International Reference Life Cycle Data System (ILCD) Handbook- Recommendations for Life Cycle Impact Assessment in the European context. First edition November 2011. EUR 24571 EN. Luxemburg. Publications Office of the European Union

Koffler (2010) On the calculation of fuel savings through lightweight design in automotive life cycle assessments. Int J Life Cycle Assess 15:128-135

Ruukki (2015) Boron steel 22MnB5 chemical composition. http://www. ruukki.com/Steel/Cold-rolled-steels/Hardenable-steels/Boron-steel22MnB5. Last accessed 24 April 2015

Salzgitter (2015) Salzgitter Flachstahl - 22MnB5 cold rolled, quenches and tempered steel, boronalloyed. - chemical composition. http:// www.salzgitter-flachstahl.de/fileadmin/mediadb/szfg/ informationsmaterial/produktinformationen/kaltgewalztes feinblech/eng/22mnb5.pdf. Last accessed 24 April 2015

SLC (2009) SuperLIGHT-CAR - Sustainable Production Technologies of Emission reduced Light-weight car concepts. LCA work package. http://www.superlightcar.com/public/index.php?option=com frontpage\&Itemid=1. Last accessed 12 May 2015

SSAB (2015) Docol 22MnB5 Cold rolled boron boron steel for hardening in water or oil. http://www.ssab.com/Global/DOCOL/ datasheets_docol/en/227_Docol_22MnB5_Cold_rolled_boron steel_for_hardening_in_water_or_oil.pdf. Last accessed 24 April 2015

ThyssenKrupp (2009) InCar-innovative modular solution kit by ThyssenKrupp 